\title{
How Less Alienation Creates More Exploitation? Audience Labour on Social Network Sites
}

\author{
Eran Fisher
}

\author{
Department of Sociology, Political Science, and Communication, The Open University, Israel, \\ eranfisher@gmail.com
}

\begin{abstract}
The notion of audience labour has been an important contribution to Marxist political economy of the media. It revised the traditional political economy analysis, which focused on media ownership, by suggesting that media was also a site of production, constituting particular relations of production. Such analysis highlighted the active role of audience in the creation of media value as both commodities and workers, thus pointing to audience exploitation. Recently, in light of paradigmatic transformations in the media environment - particularly the emergence of Web 2.0 and social network sites - there has been a renewed interest in such analysis, and a reexamination of audience exploitation. Focusing on Facebook as a case-study, this article examines audience labour on social network sites along two Marxist themes - exploitation and alienation. It argues for a historical shift in the link between exploitation and alienation of audience labour, concurrent with the shift from mass media to social media. In the mass media, the capacity for exploitation of audience labour was quite limited while the alienation that such work created was high. In contrast, social media allows for the expansion and intensification of exploitation. Simultaneously, audience labour on social media - because it involves communication and sociability - also ameliorates alienation by allowing self-expression, authenticity, and relations with others. Moreover, the article argues that the political economy of social network sites is founded on a dialectical link between exploitation and alienation: in order to be de-alienated, Facebook users must communicate and socialize, thus exacerbating their exploitation. And vice-versa, in order for Facebook to exploit the work of its users, it must contribute to their de-alienation.
\end{abstract}

Keywords: Audience labour, social media, social network sites, Marxism, political economy, exploitation

Acknowledgement: Thanks to Uri Ram for his invaluable help formulating the argument. I would also like to thank Christian Fuchs and Vincent Mosco for their constructive remarks.

\section{Audience Work in the Mass Media}

The contribution of Marxist theory to communication studies runs wide and deep (see, for example, Hardt 1992, Artz, Macek, and Cloud 2006). Two analytical coordinates to the study of media, however, stand out as particularly influential: a cultural analysis and a materialist analysis.1 The two approaches offer quite a different perspective on what it is precisely that audience does. A cultural analysis focuses on the superstructure and uncovers the ideological role of media content in the reproduction of capitalism. Such an analysis of cultural studies (Holmes 2005, 23-24) includes, for example, an investigation into the ideological content of books (Radway 1984), journals (Lutz and Collins 1993, Stevenson, Jackson, and Brooks 2001) advertisements (du Gay et al. 1997, Section 1), movies (Wasko 2001), television shows (Liebes and Katz 1994), and news (Said 1981) (see: Akass and McCabe 2007). Analyzing the undercurrent ideologies of media content could pertain to capitalist concerns, such as class, consumerism, and inequality, as well as to other concerns, such as gender, nationalism, and race (see: hooks 1996, Hall 1995).

Two intellectual legacies have been particularly central in the development of this analytical coordinate: the Frankfurt school (Adorno 2001, Horkheimer and Adorno 1976) and the Birmingham school (Hall 1980, 1995). The two schools differ in their interpretation of the workings of ideology and in the role of the audience. The Frankfurt School views ideological messages as forced down on passive audiences. This has led to study how ideology is coded into media messages. The Birmingham School attributes audience with an active capacity to decode, or "read" ideological messages in the media and resist them (Hall 1980, Mathijs 2002), leading to a theorization of audiences as participants in the construction of multiple meanings of media texts (Ang 1985, Morley 1992). Generally, then, whether assuming that ideological content is propagated top-down to audiences,

\footnotetext{
1 I use the distinction between cultural studies and political economy as ideal types, referring to categories of analysis, rather than to actual coherent schools, or individual researchers, which always tend to be more nuanced. Thus, for example, I do not argue that the Frankfurt School has dealt merely with ideology, but rather that the ideal type of cultural studies and its focus on ideology is well epitomized in the thrust of the School's work.
} 
or whether audiences are seen as actively participating in the process of meaning-making, this strand of Marxist research contributes to the analysis of the media as an ideological site.

A second dominant contribution of Marxist theory to communication studies is a materialist analysis, focusing on the "base". Such analysis of political economy uncovers the relations of production entailed in media institutions. Here, too, one can discern two dominant approaches. Predominantly, the political economy of the media focuses on media ownership. This approach analyzes media as a means of production, investigating issues of media monopoly, media corporation's mergers and consolidations, links between government and the media, and employment arrangements of media workers (Mosco 2009; Mosco and McKercher 2009; Schiller H. 1991; Schiller D. 2010; McChesney 2008; Herman and Chomsky 1988). In the 1970-80s, the political economy of the media was greatly revised by analyzing media as a site of production in and of itself, thus highlighting the productivist role of audience in the creation of media value, both as a commodity and as labour power. This approach was pioneered by Dallas Smythe's groundbreaking work on the audience commodity (Smythe 1981). Smythe suggested that what goes on in mass communication is not primarily audience consumption of media content - produced by media corporations but, in fact, the selling of audience attention to advertisers. This formulation rendered the audience as active participant in the political economy of mass communication. Smythe's notion of the work of the audience revolves particularly on cognitive and emotional work: learning to desire and buy particular brands and commodities. His was a critique of what he considered to be a "blindspot" in the aforementioned Marxist culturalist analysis, which tended to focus exclusively on the content of media products.

Rather than viewing the media merely as an ideological, superstructural apparatus, that supports relations of production in the economic base - presumably located elsewhere (for example, in the factory) - Smythe positioned the media as a vital component in the chain of capital accumulation. Smythe suggested that the media sells the audience commodity to advertisers. In return for the bait of programing, audience remains glued to the television screen, thus watching advertisements, which become an ever-important driving motor for consumption. For the first time, then, Smythe assigned the mass media and the audience central roles in advanced capitalism, arguing that the "mass media produce audience as commodities for sale to advertisers", and that "audience-power" is put to work by advertisers by "getting audiences to market commodities to themselves" (Jhally and Livant 1986, 129). In some respects, Smythe transplanted the Birmingham School's notion of the active audience, from the realm of meaning-making to that of money-making.

Further developments in this strand of Marxist political economy analyzed media as a site for the production of value in and of itself. Jhally and Livant (1986) argued that Smythe's focus on the contribution of audience labour for manufacturers of branded commodities "has tended to deflect the specificity of the analysis away from communications to the ensuing consumption behavior of the audience" (Jhally and Livant 1986, 129). "Ultimately" they say, "Smythe was concerned with drawing attention to the place of communications in the wider system of social reproduction of capital" (ibid., 129). Criticizing Smythe's heavy reliance on the use-value of messages (as motivating consumption), Jhally and Livant explore the blindspot that is "located more firmly within the media industries" (ibid., 129, emphasis in original). They therefore analyze watching as a form of working since it harnesses human "capacities of perception" (ibid., 126) to the creation of value. The creation of surplus-value in the media is based on "extra watching" of commercials, on watching more ads than are necessary to pay for programming. This "surplus watching time" (ibid., 127), then, suggests that audience, in fact, work for programmers, not advertisers.

Such analysis constructs the media as a dynamic site of struggle between audience (labour) and media providers (capital), a struggle that revolves on time. Jhally and Livant (1986) do that by employing Marx's distinction between extensive and intensive exploitation. Marx insisted that capitalist struggles ultimately revolve around time, since surplus-value can only arise from workers working more time than is actually needed to reproduce their lives. This extra working creates surplus-value which, rather than being exchanged for its equivalent, is rendered into capital and is introduced to the process of accumulation (for example, by investing in new technology). Since this entails the creation of value by one class of people (workers) and its uncompensated transference to another class (capitalists), Marx refers to that as exploitation. The problem, inherent to capitalist accumulation, is that surplus-value tends to diminish over time, dwindling away the source of capital accumulation (Marx 1993, Ch. 13). To expand, or even just conserve the rate of surplus-value, capital strives to find ways to enlarge the scope of exploitation. This is done by either of two forms: extensive exploitation and intensive exploitation. Extensive exploitation refers to techniques and arrangements by which more time is dedicated to work, for example, by elongating the working day or by cutting down on lunch breaks and vacation time. Intensive exploitation is achieved by having 
workers produce more in less time, for example, by accelerating the rhythm of work or making the work process more efficient.

Jhally and Livant (1986) argue that both these processes of exploitation have been occurring in the mass media. The audience has been asked to work more and harder over the course of history. The extension of exploitation was achieved by introducing audience with more advertisements, thus making them watch (i.e., work) more time. The intensification of exploitation, or the increase in relative surplus-value was achieved in two ways: "reorganizing the watching population, and ... reorganizing the watching process" (Jhally and Livant 1986, 133). The first involves all sorts of techniques, from media market research to the rating system, all of which are aimed at helping media corporations target a specific audience with a specific ad; such market segmentation leads to increase in the value of advertisement. As Jally and Livant put it: "Specification and fractionation of the audience leads to a form of 'concentrated viewing' by the audience in which there is .... little wasted watching" (133). Since highly targeted advertising costs more, "we can say that the audience organized in this manner watches 'harder' and with more intensity and efficiency" (Jhally and Livant 1986, 133-4). The other way by which relative surplus-value is exerted is through the division of time, accomplished mainly by shorter commercials.

\section{Mass Media Alienation}

While Marxist political economy of the media has been concerned since the 1970s with the question of exploitation in the media, little attention has been given to the notion of alienation within this framework; an oddity, considering that Marx conceived an inextricable link between the two. Marx's conception of alienation is complex and multi-layered, pertaining to a process as a well as a result. Alienation pertains to the separation of the worker from vital life processes and objects, as well as to the resulting state of estrangement from these objects. It is the estrangement of workers from the labour process, from other workers, from the finished product, and ultimately from their selves, their species-being (Marx 1978). Rather than work being an activity that workers control and navigate, rather than the real essence of a person be objectified in what he does, rather than work be a means of self-realization and authentic expression, rather than work help a person connect, communicate, and collaborate with other human beings, work under capitalism results instead in alienation.

I use the term alienation somewhat leniently, to highlight the humanist aspects in Marx's critique of capitalism and distinguish it from his more structural and economic critique. In Marxist critique, alienation and exploitation are inextricably linked, and may even be thought of as complementary tenets. Alienation is both a pre-condition for exploitation and the result thereof. Both are corollaries of the very foundations of capitalism - private property and the commodification of labour; one problem cannot be resolved without resolving the other. They do, however, point to two different aspects in Marx's critique of capitalism. The distinction is often made (following Althusser) between the young and mature Marx, the former offering a more humanist analysis of capitalism, the latter a more economistic one. While the empirical accuracy of this distinction is questionable (the mature Marx of Capital still insists on the relevance of alienation as a central cause and effect of capitalism), it does capture two distinct thrusts in Marx's critique of capitalism.

Alienation entails not only a social-economic condition whereby "value" and the product are separated from their real producers and are transferred from one class to another. More than that, alienation signals an existential state of not being in control over something (the labour process, the product, etc.), of being estranged from something (one's humanity, etc.). The thrust of this concept and the reason to introduce it over and above exploitation is precisely to highlight the contradictions of capitalism from a humanist viewpoint.

Another liberty I take with the notion of alienation is that I use the term to refer to a condition whereby work, the work process, the product of labour, and one's essence are more or less alienated. Such compromise of Marxist theoretical purity is justified in the name of historical reality. As Boltanski and Chiapello (2005) have shown, the social and political history of industrial capitalism has been one of mitigating one problem over the other, rather than eliminating both. Hence their distinction between the humanist artistic critique and the economistic social critique. In the context of this paper, less alienation refers to a greater possibility to express oneself, to control one's production process, to objectify one's essence and connect and communicate with others. Thus, for example, working on one's Facebook page can be thought of as less alienating than working watching a television program.

Watching the media is constructed as a leisure activity in liberal discourse. Media consumption is depicted as the opposite of the alienation that dominates production; a time away from the alienation of the workday, and a chance for de-alienation (as the case is for example in the prominent 
uses and gratifications theory; see Katz, Blumler, and Gurevitch 1973-4). Constructing audiencing as a consumerist activity, positions the audience in an active capacity of choice. As opposed to the work process, of which workers had no control, watching television supposedly puts the control in the hands of the viewer (literally so, with the advent of the remote control). Watching the mass media, then, is constructed in liberal discourse as a consumerist, irrational, fun, and fulfilling practice.

While Marxist political economy of the media ignored the question of alienation, the culturalistideological analysis did pay attention to some core aspects of alienation, even if not attending to the concept per se. If watching - in the capitalist media environment - is a form of working, then the process and content of that labour are also alienated from the audience. In fact, both advertisements and programs (which support the content of the advertisements) feed into and thrive on audience alienation, suggesting that self-fulfilment and objectification should and will arrive from consumption and leisure activities, rather than from work. Such themes are most extensively explored in the work of the Frankfurt School on the culture industry (Adorno 2001, Ch.6). But such analysis does not explicitly link audience exploitation to audience alienation. According to Marx, alienation and exploitation are inextricably linked and are a corollary of the very foundations of capitalism - private property and the commodification of labour. One problem cannot be resolved without resolving the other.

\section{Audience Work in SNS: The Case of Facebook}

Recently, there has been a renewed interest in the notion of audience work in light of a changing media environment, particularly the emergence of web 2.0 and social network sites (SNS). Some features of this new media environment makes a revisiting of the concept of audience labour particularly important. As opposed to mass media, SNS is characterized by high levels of participation, by user-generated content, and by the ability to create varied channels of communication: one-to-one, one-to-many, and many-to-many.

Marxist-inspired research on this new media environment has focused almost exclusively on audience exploitation. Simultaneously, mainstream (liberal) research has tended to reaffirm the common-sense and ideological construction of SNS as facilitating de-alienation by offering users opportunities for self-expression, authenticity, communication, collaboration with others, and deep engagement with, and control over cultural, social, and economic ventures.

My argument is that both these trends - seemingly contradictory - are in fact dialectically linked. Exploitation and de-alienation are not simply two contrasting interpretations of SNS; rather, Marxist theory encourages us to accommodate them within a single analytical framework. SNS give audience more opportunities for objectification by allowing self-expression, authenticity, and communication and collabouration with others. As the communication and sociability of users are commodified, so does their labour become a source for exploitation. In what follows I consider the dialectics of exploitation and alienation on SNS by taking a closer look at Facebook.

\subsection{Facebook as a Means of Communication}

What is the work that SNS users do? What is it precisely that they produce? And how are they exploited? To accommodate a dialectical analysis of Facebook we should be looking at it as both a means of communication and a means of production. That is, not only as a new form of media which allows for new modes of communication (Napoli 2010), but also as a technology that facilitates a new mode of production. This should help up overcome the shortcoming of previous Marxist analysis, which offers two divergent analyses of the media as either a means of communication or a means of production. While such dialectical approach is appropriate to any form of mass media it becomes particularly important in the new media environment, which can be defined precisely as tying communication and production more closely together. Indeed, the unique character of web 2.0 has encouraged researchers to look more carefully at the dialectics of these two coordinates (Scholz 2010, Lee 2011).

Facebook, the world's most popular SNS, was launched in February 2004 and had 845 million monthly active users at the end of December 2011 (Facebook 2012b). Facebook offers a platform where users can create personal profiles to present themselves and communicate in varying degrees of detail and complexity about their whereabouts, thoughts, feelings, and actions. Users may add other Facebook users as friends, exchange messages with them, and follow after their public messages and their whereabouts. Users may also create communities, or sub-networks, based on shared interests. The profile allows users to characterize themselves along various personal cate- 
gories, such as gender and education history, as well as through lifestyle choices, such as favorite artists and hobbies.

Users communicate with friends through various private and public tools such as "Status", which allows users to inform their friends of their whereabouts and actions; "Wall", which is the a space on every user's profile page that allows friends to post messages for the user to see; and "Chat", which allows private, synchronic communication with friends. Users may also create and join interest groups and "Like" pages, initiated and operated primarily by governmental, commercial, and non-governmental organization as means of advertisement, sale, and mobilization. The plethora of networks and communities of which Facebook users are part can generate social action - political, economic, communal, or societal - by mean of communication and organization. Facebook is reported to have an increasingly central role in facilitating and organizing social movements and political upheavals from the Anti-Globalization movement to the Arab Spring.

Facebook is inherently "biased" to communication so that even some personal activities on one's own profile automatically translate into communication. Such is the case of photo "tagging" in the Photos application, one of the most popular applications on Facebook, where users can upload albums and photos. If an uploaded photo features a user's friend, he may tag the photo. This sends an automatic notification to the tagged friend, containing a link to the photo. Thus, posting a photo may roll into a communication event.

Such banal description highlights the communication facet of Facebook, and the opportunities it facilitates for users' de-alienation, especially, as opposed to the limited opportunities facilitated by mass media. The age of mass- media was dominated by broadcast television and radio, print newspapers, and film. It was centralist, allowing only a uni-directional flow of information from few to many, and from top down. Mass-media created a hierarchical dichotomy between active producers and passive consumers, content was prepackaged and thus limited in variety, at once assuming and constructing a relatively homogenous audience. Social media, in contrast, facilitates varied communication forms: few to few, few to many, many to many. It is interactive, allowing users more engagement, and rendering the passive, homogeneous audience of mass-media into an active and engaged audience. Communication on the Internet allows individuals to narrate their lives (e.g. blogs), make their views public (talkbacks), and express their creativity (YouTube). It also allows Internet users to collabourate among themselves in an increasingly participatory culture (Jenkins 2009, Burgess and Green 2009). Indeed, most research looks at the communication facet of Facebook, and at its ability to empower individuals by contributing to their objectification.

Thus, internet research tends to construct communication - multiple, democratic, trespassing boundaries of space and time - as an ideal, most fully materialized by means of the internet. It tends to focus on user's experience with Facebook, emphasizing individual agents' purposeful use of Facebook for communication. Such "methodological individualism" (Popper 1971: Ch. 14), where individual users are the point of departure for the analysis, leads much research to focus on users' satisfaction (Bonds-Raacke and Raacke 2010, Quan-Haase and Young 2010), or on the consequences of communicating on Facebook to user's subjectivity and psychological well-being (Gonzales and Hancock 2011, Ong et al. 2011). Lastly, studies in the tradition of virtual ethnography too emphasize the communication facet of Facebook, with privacy and the dissolution of the private sphere toping research concerns (West, Lewis, and Currie 2009, Brandtzaeg, Luders, and Skjetne 2010).

These studies, then, take Facebook's mission statement - to "giv[e] people the power to share and make the world more open and connected ... Millions of people use Facebook everyday to keep up with friends, upload an unlimited number of photos, share links and videos, and learn more about the people they meet" (Facebook 2012). - at face value, and see it as a virtual space of communication, sociability, and community.

\subsection{Facebook as a Means of Production}

Having predominantly conceived as a means of communication, the public and academic discussion on Facebook tends to highlight its capacity to contribute to (or hamper) de-alienation among users. As aforementioned, my goal here is to point out how this capacity for objectification is linked with an empowered capacity for exploitation. This demands that we recall that being a commercial company, Facebook's primary mission is to accumulate capital, and that we analyze Facebook as technology and see it as galvanizing social relations. Such analysis of Facebook as a capitalist technology that facilitated and exacerbates exploitation, should then be linked to the dominant analysis of Facebook as a media for communication allowing de-alienation.

Facebook's accumulation strategy can be appreciated by proxy of its staggering market value. While Facebook's market value is highly unstable and speculative, but it can nevertheless be de- 
termined to be in the neighbourhood of US\$75-100 billion. What precisely in Facebook is worth $\$ 100 \mathrm{bb}$ ? Where does the value of Facebook emanate from? And at a more sociological level: what are the relations of production upon which SNSs are founded? We can thus begin to outline a political economy of SNS by conceptualizing Facebook not merely as a means of communication but also as technology, as embodying social relations.

A full answer to these questions should tie both facets of Facebook: as a means of communication and a means of production; to understand Facebook as technology, we need to understand Facebook as being also a media. This dialectical link of media and technology, of communication and production, is in fact a key feature of contemporary capitalist society; Facebook epitomizes a new form of production relations, where value is created not primarily by workers of the company, but by the audience. And the most important thing that Facebook users produce - the primary source of Facebook's value - is communication and sociability.

The value of Facebook is derived from Facebook's unprecedented ability to have access to information, store, own, process, and analyze it, and deliver it to its customers. Metaphorically, then, Facebook might be mistakenly seen as a warehouse of information. But the term barely begins to uncover the novelty of Facebook. To better understand the political economy of Facebook we must ask what this information consists of, how it comes into being, and by whom. To do that I will distinguish between five different types of information, which are to some extent layered one on top of the other: demographic, personal, communicative, performativite, and associational. Such typology suggests that rather than a warehouse, a more apt metaphor for Facebook is a factory, where information is produced through communication and sociability, rather than simply stored. What is new and unique about Facebook, and crucial to its political economy, is that much of the information in SNS emanates from the very practice of using it, from being a media of communication and sociability. Here it is that Facebook as a means of communication (media) and a means of production (technology) converge.

Communication between Facebook users generates a plethora of personal and social information about users, information which is becoming increasingly valuable for companies in virtually all consumer industries, and which is eagerly sought after by advertising, public relations, and marketing professionals. Some of that information is quite "lean" and can be described as demographic. SNS become key sites where demographic information is written, recorded, aggregated, and organized. The availability of demographic information on SNS is based on either users' selfdisclosure (for example, in the case of age, gender, marital status, or education), or the location of servers (in the case of geographical location). While this kind of information "precedes" Facebook, it is not completely independent of Facebook, since SNS encourage their users to self-disclosure. This has a formal manifestation in Facebook's terms of use, which forbid users to "provide any false personal information on Facebook", and directs them to "keep ... contact information accurate and up-to-date" (Facebook 2011a). Indeed, Facebook's privacy settings have been persistently designed to keep users' information as open as possible for public viewing (Fuchs 2011a, 2011b). More subtly and fundamentally, the ethics and norms that developed on SNS put premium on a genuine representation of the self. This signifies a turn from the culture of anonymity, promulgated during the early years of online sociability in forums, chat rooms, and MUDs (Turkle 1997).

This brings us to a second, 'thicker' layer of information, which pertains to the identity and authenticity of users. The ethics of SNS call for publicness, for defining and identifying oneself to oneself and to others. Users are encouraged to reveal and present their true self and define who they are through profiling. Such a demand puts users in a position of forced reflexivity, an obligation to think about, define, and present themselves. Such reflexivity is built into the website's design, which encourages users to self-disclose abundantly and systemically. As Illouz (2007, Ch. 3) has shown, profile-based websites (such as dating sites) encourage users to think about themselves in particular terms and identify themselves according to preconceived and pre-packaged categories, thus rationalizing self-disclosure. For example, when constructing a personal profile on Facebook users are asked to define their "philosophy" with the following categories: "religion", "political views", "people who inspire you", and "favourite quotes". Even though this kind of personal information presumably precedes engagement with Facebook, it cannot really be thought of as preexisting information that Facebook merely harvests, but as information which gets articulated within the specific context of social networks, i.e., that of communication and sociality.

The third layer of information is further dependent on the engagement of users with Facebook: information based on the communication content of users, on their conversations with each other. In economic terms, this is arguably the most valuable information produced by users. Indeed, the attention of companies, professionals, and applications engages in the endeavour of monetizing SNS is primarily focused on communication content. Such endeavour employs quantitative and 
qualitative methods to analyze the content of interpersonal and social communication in order to decipher what people are talking about and in what way. The analyzed trends, keywords, themes, and narratives can then be associated with demographic information (such as gender, geographical location, or age) or with behavioural information (such as consumption behaviour), and yield valuable commercial information. Such information is also highly individualized, allowing it to make a definite connection between a specific content and a specific person.

Commercial interests not only listen in to the conversation of users, but also use the SNS to initiate, engage with, and shape the conversation. They can participate in the conversation by propagating messages, creating a buzz, and designing fashions and fads. An exemplar of that is the viral message (or the meme), often originating and promulgated by public relations professionals (see: Downes 1999, Green 2010: Ch. 11). In such cases, users become the media through which messages are propagated.

While communication content on Facebook covers virtually every aspect of human communication, it is worthy to note two particular types of information that SNS is especially conducive in allowing their articulation and organization, and that are of increasing value in contemporary capitalism: mundane information, and emotional queues. Mundane information pertains to everyday expressions of lived experience, such as photos taken on a trip, or reports about one's whereabouts (Beer and Burrows 2010). These scraps of information about everyday life experiences were hitherto perceived as too fragmented, insignificant, and personal to be noticed or reported on in public. SNS is especially fit to host this kind of information, which in turn opens up a capillary gaze at the way people live. Emotional queues pertain to subjective emotional expressions, and to emotional characterizations which accompany the communication. Emotional queues are usually tied to some activity done by users, such as reading a news story, or waiting in line at the supermarket. The ever-presence and immediacy of social media through mobile devices means that sentiments are registered and expressed almost as they occur, rather than reported upon in retrospect. SNS because they are personal, interpersonal, and social; because they are associated with leisure activities and sociability; because they encourage people to be expressive, frank, and above all communicative - are particularly apt for the production and extraction of such types of information.

The forth layer of information is performativite, pertaining to quantitative and qualitative characteristics of users' activities on SNS, such as the number of friends they have, the dynamics of the sub-networks of which they are part, their level of engagement with Facebook, time spent on Facebook, type of activities (number of posts, number of photos posted, number and nature of "likes" clicked) and so forth.

The fifth and last layer of information, closely related to the previous one, is associational. This refers to the very formation of sub-networks within the SNS: a user's link to other profiles, to commercial and political pages, to news stories, brands, and so forth. By forming networks of associations, users are producing webs of meaning, symbolic universes, and semantic fields. Association information is valuable in further identifying and characterizing individuals. In a postmodern culture, where identity is constructed through signs, the web of "Likes" that users form serves as an indicator of their identity. Associational information may therefore be valuable in uncovering correlations between indicators. Moreover, the sub-networks that are formed are highly valuable since they are likely to have an identifiable character; in public relations terms, sub-networks are highly segmented groups, because opt-in is voluntary and based on some manifest characteristic. Thus, associational information allows public relations professional to identify (as well as construct) groups based on their positive attitudes towards a material, service, or cultural product, follow the different layers of information they produce, and engage these groups directly (for example, by creating a buzz).

Beginning from the most basic demographic information to the most sophisticated, it is not merely pre-existing personal information that SNS now make easier to collect. More dramatically, the existence of much of this information is dependent on the very use of SNS, on people joining them and conducting large parts of their life in them; it is information that comes into being in the very act of communicating and socializing. In sum, my argument is that such types of information which are of increasing value in contemporary economy - are dependent on a means of communication to be produced.

\section{The Dialectics of Exploitation and Alienation on SNS}

Marxist theory, then, introduced two coordinates to the analysis of the media: a culturalist, ideology approach, and a materialist, political economy approach. In more abstract terms, these two coordinates refer to two distinctive facets of media as either a means of communication or a means of production. Notwithstanding Marx's insistence on a dialectical analysis of society, Marxist studies of the media commonly employ either of these two coordinates (Fenton 2007). This is not to say 
that such studies are flatly undialectical, but rather, that dialectics is not internalized into the analysis of media. Thus, for example, culturalist analysis shows how media products such as television programs work ideologically to support relations of production in general, not in the media particularly.

Scholarship on the political economy of new media, and on audience labour in particular, also tended to be relatively one-sided, highlighting SNS as a site of exploitation of "free labour" (Terranova 2004, Ch. 3). Such approach has been criticized as over-deterministic, structuralist, and functionalist (Caraway 2011). Rather than underscoring media as a site of struggle between labour and capital, such approach gives a one-sided analysis, that of capital. The crux of Smythe's argument is that with mass communication all time becomes productive time, an argument later to be much developed with the notions of the social factory, and immaterial labour. Caraway argues that such framework is unable to distinguish leisure time from work time, coerced labour from free labour, and capacity to work from willingness to work. This lack of distinctions, says Caraway, obfuscate the Marxist category of labour. He questions Smythe's historical narrative, according to which a decrease in factory labour time was complemented by an increase in labour time in front of media advertisements. Caraway suggests an alternative version which endows labour with agency. According to the alternative version, the reduction in working hours, and the corollary expansion of leisure time were a result of a persistent and bloody struggle of workers at the beginning of the 20th century. More theoretically, then, Caraway (2011) argues that the critical potentials of the notions of the social factory and immaterial labour are absent from contemporary accounts. And Scholz has emphasized the dialectical relations between Facebook as playground and as factory (Scholz 2010).

Following this line of inquiry, this paper has attempted to explore the dialectics of production and communication within contemporary media forms, both building on the work of Smythe (1981) and Jhally and Livant (1986), and updating it. It argues that the extension and intensification of exploitation of audience labour in the mass media ran into relatively low barriers. The extension of exploitation was limited by the capacity of viewers to watch advertisements. Watching television ads is not something that audience commonly enjoys. The media cannot therefore screen too many ads from fear of losing viewers' attention (which is the actual labour power that it sells to advertisers). New technologies of television viewing which allow audience more control over viewing (such as TIVO) are setting further limits on exploitation since they allow audience to skip over ads.

The intensification of exploitation is also fairly limited by two parameters. First, the monitoring, rating, and segmentation system of mass media is highly expensive.2 Moreover, it is imbued in a paradox: the more accurate the information on viewers is, the more the surplus-value of watching increases (Jhally and Livant 1986). However, such increase in value is somewhat undermined by the price of collecting more accurate information. Moreover, viewers' monitoring techniques are based on statistical analysis, and are hence inaccurate and unreliable by definition. The desires, personality, and behaviour of each and every individual in the audience of the mass media are hard to gauge. The second parameter which sets limits to the intensification of exploitation in the mass media is that the intensification of exploitation requires media corporations to create programs that provide the appropriate "bait" for the desired audience. They can fail miserably achieving this task, either by not attracting enough audience, or not attracting a desired segment of the audience.

SNS offer a transcendence of these limitations, allowing the extension and intensification of exploitation to go beyond the limits that the mass media set. The extension of exploitation is achieved by having users spend more time on SNS. The work of Facebook users is done incessantly. In January 2010 Facebook became the site where U.S. web users spend most time (Parr 2010). The average web user spends more time on Facebook than on Google, Yahoo, YouTube, Microsoft, Wikipedia and Amazon combined (Parr 2010). The Nielsen rating for that month revealed that the average American user spends more than seven hours a month on Facebook, or 14 minutes per day. And American Facebook users are not even the heaviest users. An industry study of the monitoring and analysis firm Experian from September 2011 found that Facebook is most heavily used in Singapore, where the average visit to the social network lasts more than 38 minutes (Emerson 2011).

Moreover, thanks to the ubiquity of mobile devices (from laptops to smartphones) and wireless networks (from Wi-Fi to 3G) users are almost always accessible to Facebook. Compared with television watching, which is spatially fixed and temporally limited, Facebook offers a much more flexi-

\footnotetext{
2012).

${ }^{2}$ For example, the 2011 revenues of Nielsen, the largest global media rating company, were over $\$ 5.5$ billion (Nielsen
} 
ble usage patterns. More time, than, in more parts of the day (work day, leisure time) can be spent communicating and socializing on Facebook. Self-surveillance technologies, such as Foursquare or Facebook Places (or: Location) also put users at an arms-length from their friends, extending the duration they are likely to be active on the social network.

SNS allow also the intensification of exploitation. Rather than mass media corporations allocating resources to monitor and segment their audience, it is users of SNS that segment themselves in a manner that can only be dreamt of for television audience. Such procedure is much cheaper, as it is in effect "outsourced" to users, who act as produsers (Bruns 2008). Moreover, the information gathered about the audience is also much more accurate and thick. Whereas the mass media knew its audiences as statistical entities, as aggregates and abstract segments, Facebook knows its users as individuals. The capillary reach of SNS, then, facilitates the intensification of exploitation; a biopolitical nervous system which harnesses the immaterial labour of users.

This puts into question a central tenet of the Autonomist interpretation of Marxism. The notions of immaterial labour and general intellect suggest a process of deterritorialization of knowledge, the prime means of production of contemporary capitalist accumulations. Virno speaks of "a repository of knowledges indivisible from living subjects and from their linguistic co-operation" (Virno 1996, quoted in Dyer-Witheford 1999, 222, emphasis mine). Such knowledges are hard to locate, localize, and collect, since they are "produced" during leisure time, within private spaces, and within the communicative space between individuals, as part of their everyday lives. The analysis presented here suggests we should think about SNS as a technology for the reterritorialization of the kind of labour that produces such knowledges - immaterial labour - and the kind of knowledges that are produced - general intellect (Peterson 2008).

Hence, the extension and intensification of exploitation in social media compared with mass media relies on the unprecedented ability to harness new forces of production to the accumulation process, particularly the production of information through communication and sociability. The audience of SNS creates value simply by audiencing, by using the media platform to express itself, communicate, and socialize. Such exploitation, then, is conditioned by a promise for de-alienation. SNS offer a media environment where audience work can potentially lead to objectification: users have much more control over the work process and the product (although not owning it legally); work entails communication that helps users connect with others and objectify more facets of their species being. SNS is a space for self-expression, for making friends, constructing communities, and organizing a political, cultural, social, or economic action.

The two processes that SNS facilitates - the exacerbation of exploitation and the mitigation of alienation - are not simply co-present but are dialectically linked. SNS establishes new relations of production that are based on a dialectical link between exploitation and alienation: in order to be de-alienated, users must communicate and socialize: they must establish social networks, share information, talk to their friends and read their posts, follow and be followed. By thus doing they also exacerbate their exploitation. And vice-versa, in order for Facebook to exploit the work of its users, it must contribute to the de-alienation of their users, propagating the ideology that dealienation can in fact (and solely) be achieved by communicating and socializing on SNS, an ideology of communication, networking, and self-expression (Dean 2010), which sees network technology and social media in particular as the golden route to de-alienation. In such ideology, alienation is linked with a lack of communication and with social isolation, a malady promised to be cured through communication and through SNS. And so, the more users communicate and socialize, the more they post photos and follow their friends, the more they "Like" - in short, the more they engage in authentic self-expression and interpersonal communication - the more they objectify and de-alienate. Put differently, the more they work, the more they create surplus-value, and the more they are exploited.

\section{A Closed-Circuit of Communication and Production}

The case of Facebook alludes to new relations of production, emerging within a new environment of social media. The new relations of production are markedly different from those crystallized in the mass media, and theorized by Smythe (1981) and Jhally and Livant (1986). They are based on a new trade off between exploitation and alienation. In comparison with mass media, and television in particular, SNS can be conceptualized as a technology that is able to extend and intensify exploitation, while at the same time alleviating alienation. Audience work on SNS is both more exploitative and more de-alienating. In fact, the capacity of SNS to exploit audience work is dependent on its capacity to alleviate alienation. SNS users work harder - producing more information, communication, and sociability - the more they perceive this work to be de-alienating. 
Recently, there has been an emerging interest in the question of audience work and exploitation. In two complementary chapters, Andrejevic (2011a, 2011b) examines the application of the categories of exploitation and alienation, respectively, to analyze the political economy of social media. Andrejevic suggests that social media users can be thought of as alienated from their media labour only to the extent that they do not control the product on which they labour (Andrejevic 2011b). He distinguishes between two types of information that are subject to exploitation on social media: intentional/ unintentional information. The former pertains to data extracted from intentional actions of users (such as posting a photo, or tweeting), while unintentional information pertains to data that users produce unintentionally, while doing something else. The generation of unintentional data can be described, according to Andrejevic, "as the alienated or estranged dimension of their activity" (2011b, 85). My suggested categorization of the types of information produced by users suggests that such distinction is hard to make, and is therefore a problematic basis to discern alienated labour from unalienated one. Most data that users produce has a dual character: while being intentional, posting a photo also produces unintentional information such as the web of users that are exposed to the photo or comment on it.

My contentions in this article rely on a different understanding of alienation as a relative entity, arguing that within capitalism workers can be more or less alienated. Hence, I suggest that the relations of production entailed by social media are based on an implicit social contract which allows media companies to commodify the communication produced by users (i.e., exploiting them) in return for giving them control over the process of producing communication, and expanding their opportunity for de-alienation.

Andrejevic does point to the complexity of the relations between social media users and companies. Indeed he defines the challenge of employing the notion of exploitation in the context of social media as being about explaining "the relationship between willing participation and commercial exploitation" (2011a, 83). And suggests that to account for exploitation on social media we must also appreciate that the work of the audience is a source for enjoyment for users, and a way to "overcome alienation in the realm of consumption" (Andrejevic 2011b, 80). But he does not suggest a direct link between the two.

The dialectical link between media as a means of communication and media as a means of production in SNS and web 2.0 has been most productively theorized with the notion of immaterial labour (Virno and Hardt 2006). Indeed, Smythe's analysis forestalls this concept by pointing to the commodification of audience attention, i.e., the mobilization of its cognitive faculties for capitalist accumulation. Immaterial labour (and in other contexts: general intellect [Virno 2001]) pertains to a creative force of cognitive, emotional, and communicative capacities that are located within individuals, not factories. One of the key tenets of this analytical category, developed by the Italian Autonomist Marxist School, is that such productive potentials of human life and lived experience is extremely difficult to be harness, contain, or structure by capital. Hence, the increased reliance of capitalism on immaterial labour holds a revolutionary potential.

The dialectical analysis of the media presented here, however, suggests another interpretation, by taking into account the media within which such labour is carried out. Such analysis suggests that SNS offer precisely that space, that factory, which allows the extraction of these human potentialities and their subsumption by capital. As Napoli puts it, "the creative work of the audience is an increasingly important source of economic value for media organizations" (Napoli 2010, 511). Revisiting the notion of audience work on web 2.0, Napoli theorizes new media as mass communication, arguing that the term is flexible enough to account for audiences in contemporary media environment. The revolutionary nature of web 2.0 lies not in the ability of ordinary individuals to generate content, but in their newfound ability to distribute their content widely through the web (Napoli 2010). Napoli, then, directs us at circulation, not production, as the lynchpin of audience work in contemporary media environment, circulation that, as we have seen, is part and parcel of capital accumulation on SNS. If, as Napoli suggests, new media is mass communication, with the distinction that now more individuals are able to reach mass audience, then new media can be thought of as media which allows for far greater quantities of information (content) to be produced freely by far more people, and run over far greater numbers of channels of communication.

What is particularly unique in SNS is that they create an autarchic economic system, a closedcircuit of communication and production in a way that was fairly limited in the mass media age. Lee (2011) shows how Google's advertising program creates a self-propelling mechanism for the creation of exchange-value. The company "vertically integrates the search engine, the advertising agency, and the rating system" (434). Thus, for example, Google sells keywords for advertisers, allowing them to feature ads when particular words are searched. Such keywords, Lee notes, have no use-value, and in fact only have exchange-value within the Google universe, "within Google 
AdWords" (Lee 2011, 440, emphasis in original). Cohen (2008) and Fuchs (2011a, 2011b) also highlight the integration of few distinct moments along the circulation of capital within SNS. Their respective works shows how, within the context of SNS, surveillance becomes a means of commodifying the information that users produce. Fuchs (2011a) offers a Marxist political economy perspective to understand surveillance over SNS users conducted by companies as an alternative to the liberal "civilian" perspective. Such surveillance is not aimed primarily at political control by states, but is rooted in a capitalist desire to commodify information. Fuchs (2011a) highlights the contradictory nature of surveillance and privacy in contemporary society. While capitalism is conditioned by the requirement for privacy (for ex., of bank accounts and holdings) to legitimate wealth inequality, it also promotes surveillance of workers in order to tighten control over them and render the accumulation process more efficient.

Indeed, the political economy of SNS is unique in allowing the integration and conflation of previously distinct processes of production, circulation, and consumption. Not only are they taking place at the same site, but they are also feeding into each other. The production of information by users is monitored, aggregated, analyzed, and rendered into information commodities which are further consumed by users, and so on.

Immaterial labour, the productive force that propels the valorization of SNS, embodies this dual character of exacerbating exploitation and enabling de-alienation. On the one hand, immaterial labour, in comparison with material labour, has a greater potential to be enjoyable, involve personal, idiosyncratic components, carried out during leisure time or even be perceived as a form of leisure activity, playful, emotional and communicative. On the other hand, to the extent that such labour is performed on SNS, it is also commodified and entails the creation of surplus-value.

As we have seen, Facebook, too, operates as a closed system that is able to commodify communication and sociability. Thus, for example, exchange-value arises from the links created between users by users. Such links become informational commodities because companies can learn from them about consumers' behaviours. But they also serve as channels of communication (i.e., as media) for the propagation of commercial messages. In summary, the audience in SNS is a commodity (sold to advertisers), a labour power (producing communication), and media (a means of communication) through which commercial messages are distributed.

\section{Conclusion}

Table 1 summarizes the argument. In the mass media the exploitation of audience work is fairly limited. The nature of the exchange between media corporations and their working audience is programming (which acts as "wages") for watching advertisements ("labour"). Surplus-value arises from extra-watching (Jhally and Livant 1986), from producing value that exceeds that value needed to produce the programming. In comparison, the level of exploitation in social media is more intensive and extensive. Here, the media itself, i.e., the platform ("wages") is exchanged for the audience work of communicating and socializing ("labour"). Surplus-value arises from extracommunicating, from producing thicker, more textured information than is possible for individual users to use.

\begin{tabular}{|l|c|c|}
\hline & Exploitation & Alienation \\
\hline $\begin{array}{l}\text { Mass } \\
\text { media }\end{array}$ & $\begin{array}{c}\text { Low } \\
\text { Exchange: Programming for adver- } \\
\text { tisement }\end{array}$ & $\begin{array}{c}\text { High } \\
\text { Passivity } \\
\text { Paerarchy }\end{array}$ \\
\hline $\begin{array}{l}\text { Social } \\
\text { media }\end{array}$ & $\begin{array}{c}\text { High } \\
\text { Exchange: Platform for communica- } \\
\text { tion }\end{array}$ & $\begin{array}{c}\text { Low } \\
\text { Engagement } \\
\text { Authenticity }\end{array}$ \\
\hline
\end{tabular}

Table 1: Shifts in levels of exploitation and alienation in different media environments.

Alienation of the working audience in the mass media is relatively high. Television audience remains unidentifiable and anonymous to media corporations. Such audience is principally passive, merely choosing the programs it watches. The mass media also constructs a clear hierarchy be- 
tween the producers of content and its consumers. Alienation of the working audience in social media is lower. The audience is actively engaged in the production of media content. Audiencing entails deep engagement with the media, opening up the opportunity for authentic self-expression, and for communication and collaboration with others. Lastly, a high level of exploitation of audience work enabled by social media is dialectically linked with a low level of alienation. Higher levels of exploitation are dependent on high intensity of communication and sociability, which, in turn, are dependent on the affordances that SNS allow for de-alienation.

\section{References}

Adorno, Theodor. 2001. The Culture Industry: Selected Essays on Mass Culture. New York: Routledge.

Adorno, T. W. 1976. Television and the Patterns of Mass Culture. In The Critical View of Television, edited by Horace Newcomb. New York: Oxford University Press.

Akass, Kim, and Janet McCabe. 2007. Analysing Fictional Television Genres. In Media Studies: Key Issues and Debates edited by Eoin Devereux, 283-301. London: Sage.

Altucher, James. 2011. Why Facebook is Worth $\$ 50$ Billion, The Wall Street Journal, January 5. http://blogs.wsj.com/financial-adviser/2011/01/05/why-Facebook-is-worth-50-billion/.

Andrejevic, Mark. 2011a. Social Network Exploitation. In A Networked Self: Identity, Community, and Culture on Social Network Sites, edited by Zizi Papacharissi, 82-101. New York: Routledge.

Andrejevic, Mark. 2011b. Exploitation in the Data Mine. In Internet and Surveillance: The Challenges of Web 2.0 and Social Media, edited by Christian Fuchs, Kees Boersma, Anders Albrechtslund, and Marisol Sandoval, 71-88. New York: Routledge.

Ang, len. 1985. Watching Dallas: Soap Opera and the Melodramatic Imagination. London: Methuen.

Artz, Lee, Steve Macek, and Dana Cloud, eds. 2006. Marxism and Communication Studies: The Point is to Change It. New York: Peter Lang Publishing.

Beer, David, and Roger Burrows. 2010. Consumption, Prosumption and Participatory Web Cultures, Journal of Consumer Culture 10 (1): 3-12.

Boltanski, Luc and Ėve Chiapello. 2005. The New Spirit of Capitalism. New York: Verso.

Bonds-Raacke, Jennifer, and John Raacke. 2010. MySpace and Facebook: Identifying Dimensions of Uses and Gratifications for Friend Networking Sites. Individual Differences Research 8 (1): 27-33.

Brandtzaeg, Petter, Marika Luders,and Jan Haavard Skjetne. 2010. Too Many Facebook "Friends"? Content Sharing and Sociability Versus the Need for Privacy in Social Network Sites. International Journal of Human-Computer Interaction 26 (11-12): 1006-1030.

Bruns, Axel. 2008. Blogs, Wikipedia, Second Life, and Beyond: From Production to Produsage. New York: Peter Lang.

Burgess, Jean and Joshua Green. 2009. YouTube: Online Video and Participatory Culture. Oxford: Polity.

Caraway, Brett. 2011. Audience labour in the new media environment: A Marxian revisiting of the audience commodity, Media, Culture, and Society 33 (5): 693-708.

Cohen, Nicole. 2008. The Valorization of Surveillance: Towards a Political Economy of Facebook. Democratic Communiqué 22 (1): $5-22$

Dean, Jodi. 2010. Blog Theory: Feedback and Capture in the Circuits of Drive. Cambridge: Polity.

Downes, Stephen. 1999. Hacking Memes, First Monday 4 (10), available at http://firstmonday.org/htbin/cgiwrap/bin/ojs/index.php/fm/article/view/694/604.

du Gay, Paul, Stuart Hall, Linda Janes, Hugh Mackay, and Keith Negus. 1997. Doing Cultural Studies: The Story of the Sony Walkman. London: Sage.

Dyer-Witheford, Nick. 1999. Cyber-Marx: Cycles and Circuits of Struggle in High Technology Capitalism. Urbana: University of Illinois Press.

Economist, The. 2012. The Value of Friendship. February 4. http://www.economist.com/node/21546020.

Emerson, Ramona. 2011. Facebook Use By Country: See Who Spends The Most Time Social Networking. The Huffington Post. October 1. http://www.huffingtonpost.com/2011/09/30/facebook-use-bycountry_n_987722.html\#s379259\&title=1_Singapore.

Facebook. 2012a. Information page. http://www.facebook.com/facebook?v=info.

Facebook. 2012b. Newsroom. http://newsroom.fb.com/content/default.aspx?NewsAreald=22.

Fenton, Natalie. 2007. Bridging the Mythical Divide: Political Economy and Cultural Studies Approaches to the Analysis of the Media. In Media Studies: Key Issues and Debates, edited by Eoin Devereux, 7-31. London: Sage.

Foreman, Tom. 2011. How Much is Facebook Really Worth? CNN, March 8. http://articles.cnn.com/2011-0308/tech/Facebook.overvalued 1 mark-zuckerberg-Facebook-worldwide-users? s=PM:TECH.

Fuchs, Christian. 2011a. An Alternative View of Privacy on Facebook. Information 2: 140-165.

Fuchs, Christian. 2011b. Web 2.0, Prosumption, and Surveillance. Surveillance and Society 8 (3): $288-309$.

Gonzales, Amy, and Jeffrey Hancock. 2011. Mirror, Mirror on my Facebook Wall: Effects of Exposure to Facebook on SelfEsteem. CyberPsychology, Behavior \& Social Networking 14 (1/2): 79-83.

Green, Andy. 2010. Creativity in Public Relations ( $4^{\text {th }}$ ed.). London: Kogan

Hall, Stuart. 1980. Encoding/decoding. In Culture, Media, Language, edited by Stuart Hall, A. Lowe, and P. Willis. London: Hutchinson.

Hall, Stuart. 1995. The Whites of their Eyes: Racist Ideologies and the Media. In Gender, Race and Class in Media, edited by Gail Dines and Jean Humez, 18-23. London: Sage.

Hardt, Hanno. 1992. Critical Communication Studies: Essays on Communication, History and Theory in America. New York: Routledge.

Herman, Edward, and Noam Chomsky. 1988. Manufacturing Consent: The Political Economy of the Mass Media. New York: Pantheon.

Holmes, David. 2005. Communication Theory: Media, technology, Society. London: Sage.

hooks, Bell. 1996. Reel to Real: Race, Sex, and Class at the Movies. New York: Routledge.

Horkheimer, Max, and Theodor Adorno. 1976. Dialectics of enlightenment. New York: Continuum. 
Illouz, Eva. 2007. Cold Intimacies: The Making of Emotional Capitalism. Cambridge: Polity.

Jenkins, Henry. 2009. Confronting the Challenges of Participatory Culture: Media Education for the 21st Century. Cambridge: MIT Press.

Jhally, Sut, and Bill Livant. 1986. Watching as Working: The Valorization of Audience Consciousness, Journal of communication 36 (3): 124-143

Katz, Elihu, Jay G. Blumler, and Michael Gurevitch. 1973-4. Uses and Gratifications Research, The Public Opinion Quarterly 37 (4): 509-523.

Liebes, Tamar, and Elihu Katz. 1994. The Export of Meaning: Cross-Cultural Readings of Dallas. Cambridge: Polity.

Lee, Micky. 2011. Google Ads and the Blindspot Debate. Media, Culture, and Society 33 (3): 433-447.

Lutz, Catherine, and Jane Collins. 1993. Reading National Geographic. Chicago: The University of Chicago Press.

Marx, Karl. 1978. Economic and Philosophical Manuscripts of 1844. In The Marx-Engels Reader, edited by Robert Tucker, 70-91. New York: Norton \& Company.

Marx, Karl. 1990. Capital, Vol. 1. New York: Penguin Books.

Marx, Karl. 1993. Capital, Vol. 3. New York: Penguin Books.

Mathijs, Ernest. 2002. Big Brother and Critical Discourse: The Reception of Big Brother Belgium. Television and New Media 3 (3): 311-22.

McChesney, Robert. 2008. The Political Economy of Media: Enduring Issues, Emerging Dilemmas. New York: Monthly Review Press.

Mosco, Vincent. 2009. The Political Economy of Communication. Thousand Oaks: Sage.

Mosco, Vincent, and Catherine McKercher. 2009. The Labouring of Communication: Will Knowledge Workers of the World Unite? Lanham, MD: Lexington Books.

Morley, David. 1992. Television, Audiences and Cultural Studies. New York: Routledge.

Napoli, Philip. 2010. Revisiting 'Mass Communication' and the 'Work' of the Audience in the New Media Environment, Media, Culture and Society 32 (3): 505-516.

Nie/sen. 2012. Financial Information: Income Statement. http://ir.nielsen.com/reports. aspx?keyreport=592\&iid=4260029.

Ong, Eileen, Rebecca Ang, Jim Ho, Joyclynn Lim, Dion Goh, Chei Lee, and Alton Chua. 2011. Narcissism, Extraversion and Adolescents' Self-Presentation on Facebook. Personality \& Individual Differences 50 (2): 180-185.

Parr, Ben. 2010. Facebook is the Web's Ultimate Timesink. Mashable, February 17. http://mashable.com/2010/02/16/facebook-nielsen-stats/.

Peterson, Soren Mork. 2008. Loser Generated Content: From Participation to Exploitation. First Monday 13 (3).

Popper, Karl. 1971. The Open Society and its Enemies, Vol. 2. Princeton: Princeton University Press.

Quan-Haase, Anabel, and Alyson Young. 2010. Uses and Gratifications of Social Media: A Comparison of Facebook and Instant Messaging. Bulletin of Science, Technology \& Society 30 (5): 350-361.

Radway, Janice. 1984. Reading the Romance: Women, Patriarchy, and Popular Literature. Chapel Hill: University of North Carolina Press.

Said, Edward. 1981. Covering Islam: How the media and the experts determine how we see the rest of the world. New York: Pantheon Books.

Schiller, Dan. 2010. How to Think about Information. Chicago: University of Illinois Press.

Schiller, Herbert. 1991. Culture, Inc.: The Corporate Takeover of Public Expression. New York: Oxford University Press.

Scholz, Trebor. 2010. Facebook as playground and factory. In Facebook and Philosophy: What's on Your Mind?, edited by D.E. Wittkower, 241-52. Chicago: Open Court.

Smythe, Dallas. 1981. Dependency Road: Communication, Capitalism, Consciousness and Canada. Norwood: Ablex.

Spears, Lee, Brian Womack, and Ari Levi. 2012. Facebook's Epic Offering by the Numbers. Bloomberg Businessweek, February 2. http://www.businessweek.com/magazine/facebooks-epic-offering-by-the-numbers02022012.html?campaign_id=rss_search.

Stevenson, Nick, Peter Jackson, and Kate Brooks. 2001. Making Sense of Men's Magazines. Cambridge: Polity Press.

Terranova, Tiziana. 2004. Network Culture: Politics for the Information Age. London: Pluto Press.

Turkle, Sherry. 1997. Life on the Screen: Identity in the Age of the Internet. New York: Simon \& Schuster.

Virno, Paolo. 2001. General Intellect. In Lessico Postfordista, edited by Adelino Zanini and Ubaldo Fadini. Milano: Interzone [Italian, translated by Arianna Bove]. http://www.generation-online.org/p/fpvirno10.htm.

Virno, Paolo, and Michael Hardt. 2006. Radical Thought in Italy: A Potential Politics. Minneapolis: University of Minnesota Press.

Wasko, Janet 2001. Understanding Disney: The Manufacture of Fantasy. Cambridge: Polity.

Wasko, Janet, Vincent Mosco, and Manjunath Pendakur. 1993. Illuminating the Blindspots: Essays Honoring Dallas W. Smythe. Norwood: Ablex Publishing Corporation.

West, Anne, Jane Lewis, and Peter Currie. 2009. Students' Facebook 'Friends': Public and Private Spheres. Journal of Youth Studies 12 (6): 615-627.

\section{About the Author}

Eran Fisher

Eran Fisher is an Assistant Professor at the Department of Sociology, Political Science, and Communication, The Open University, Israel. He studies the intersection of new media and capitalism. His book, Media and New Capitalism in the Digital Age (2010, Palgrave), offers a critical analysis of the discourse on digital, network capitalism. 